\title{
An Integrated Framework for Diffusion of e-SCM by SMES in Sub- Saharan Africa
}

\author{
Ahmed Musa \\ Department of Management Studies Education \\ University of Education Winneba, Kumasi \\ Faisal Iddris \\ Department of Marketing, Halmstad University \\ Halmstad, Sweden
}

\begin{abstract}
The purpose of this study is to examine factors affecting electronic supply chain management (e-SCM) adoption and diffusion by Small and Medium Enterprises (SMEs) and to propose an integrative framework for successful management of e-SCM by SMEs in Sub-Saharan Africa. In this study we review existing literature and make some propositions for future empirical research. Building on existing framework this study integrates innovation diffusion theory, upper echelon theory, technology, organisation, environmental model and institutional theory and propose an integrated framework for e-SCM adoption and diffusion. The paper presents a contribution in the field of e-SCM, especially for SMEs in SubSaharan Africa.
\end{abstract}

Keywords: Electronic Supply Chain Management (e-SCM), Innovation, e.business, Technology-Organisation-Environment (TOE), Upper Echelon Theory (UET)

\section{INTRODUCTION}

Existing literature has shown that many SMEs are still not implementing e-SCM (Alam \& Ahsan, 2007), even though, e-SCM is emerging as powerful strategic tool in helping businesses achieve shorter sales period, reduction in cost of sales, better cooperation with suppliers and customers and overall operational efficiency. Giménez and Lourenço (2008) define e-SCM "as the impact that internet has on integration of key business processes from end-user through original suppliers that provide products, services and information that add value for customers and stakeholders". Hence it is important to understand the adoption and diffusion of e-SCM by SMEs. It appears from literature that research on e-SCM adoption by SMEs in Sub-Saharan Africa is scarce, and that most of the Internet-based studies is conducted in advanced economies with mature markets (Zhu, Kraemer, \& Xu, 2006). Thus, Zhu et al. (2006) has called for theories developed in industrial countries to be re-examined in the context of less developing countries. In addition, some of the recent studies reviewed on internet application by SMEs in Africa (Awa, Awara, \& Lebari, 2015; Guercini \& Runfola, 2015; Iddris, 2012; Molla \& Licker, 2005a; White, Afolayan, \& Plant, 2014), had focused on e-Commerce neglecting the area of e-SCM adoption and diffusion. This paper focuses filling this gap in literature by studying factors affecting e-SCM adoption and diffusion by SMEs and to propose an integrative framework for successful management of e-SCM by SMEs in Sub-Saharan Africa.

This paper is structured as follows. In the next section, the existing literature on e-SCM innovation and innovation assimilation is reviewed. Thereafter, the theoretical model of the study is presented, followed by some developed propositions to address e-SCM capability 
issues which may confront SMEs in Sub-Saharan Africa in an attempt to adopt and use this innovations, finally conclusion and suggestions for future study is presented.

\section{Previous e-SCM research}

\section{LITERATURE REVIEW}

Skjøtt-Larsen, Kotzab, and Grieger (2003) integrated transaction cost theory, network theory, resource-based theory into a model for analysing and reducing uncertainty and formulating strategies e-SCM. Regarding empirical studies. Lancaster, Yen, and Ku (2006) provided an overview of e-SCM initiatives by focusing on technological and evolution drives of companies' readiness to move to the web, they provided a framework and analysis of online platform for firms in transportation sectors, automotive, financial services, retail and technology. In a related study, Sambasivan, Abidin, Mohamed, and Nandan (2009) developed: web-enabled service metric, data reliability metric, time and cost metric, invoice presentation and payment metric and e-document as measures for monitoring supply chain performance management. Ke, Liu, Wei, GU, and Chen (2006) studied the factors affecting firm's e-SCM adoption by integrating relational exchange theory, institutional theory, organisational culture and information system theory. Their study reveals that normative and coercive pressures lead firms to adopt e-SCM. Cagliano et al. (2015) proposed a systemic methodology to enhance the diffusion of smartphone based service enabling supply chain e-SCM.

In the context of SMEs, Chang and Tsia (2006) identified supporting capacity of system supplier, relative advantage, organisational scale, and fundamental construction of interior informational technology as the major critical factors of e-SCM adoption by SMEs. Furthermore, a survey conducted by Archer, Wang, and Kang (2008) on the adoption of e-SCM by SMEs in Canada found that the main barriers to the adoption of e-SCM are lack of knowledge, resistance to change and lack of perceived need. Dwivedi, Papazafeiropoulo, Ramdani, Kawalek, and Lorenzo (2009) empirically examined enterprise systems (ERP, SCM, eProcurement) adoption by SMEs. The study concluded that, firms with greater perceived relative advantage, greater top management support, a larger size, greater organisational readiness are more likely to adopt enterprise systems including e-SCM.

Recent studies on internet adoption in SMEs in Africa (Awa et al., 2015; Guercini \& Runfola, 2015; Iddris, 2012; Molla \& Licker, 2005b; Uzoka, 2008; White et al., 2014) focused on eCommerce adoption and neglecting the crucial role of e-SCM in SMEs operations. For example, the results of Awa et al. (2015) show that SMEs in Nigeria are yet to exploit the full potentials of e-commerce solutions. The inability of SMEs to utilize e-SCM technology leads to general question as to why SMEs fails to tap into business opportunities created by Internet technology in Sub-Saharan Africa. The literature reviewed above shows that e-SCM adoption was have been harnessed and deployed in advance economies. This means that adoption of e-SCM by SMEs in Sub-Saharan Africa is unexplored. Thus, this study will contribute to the existing literature on e-SCM adoption.

\section{THEORETICAL DEVELOPMENT}

Several studies have focused on identifying the main determinants influencing technology related product/services (Martin \& Matlay, 2001; Thong, 1999; Venkatesh \& Davis, 2000; Venkatesh, Morris, Davis, \& Davis, 2003) these researchers investigated determinants of technology adoption of related products/services in different disciplines using variety of theoretical dimensions. The most widely used theoretical studies includes: The Theory of Planned Behaviour (TPB) (Ajzen, 1991; Ajzen \& Fishbein, 2005; Mathieson, 1991; Taylor \& Todd, 1995) Technology Acceptance Model (TAM) (Davis, Bagozzi, \& Warshaw, 1989; Venkatesh \& Davis, 1996) The Social Cognitive Theory (SCT) (Compeau, Higgins, \& Huff, 1999; 
Compeau \& Higgins, 1995; Hill, Smith, \& Mann, 1987) and Innovation Diffusion Theory (IDT) (Moore \& Benbasat, 1991; Rogers, 1995; Rogers, 2003; Rogers, 1998) and Institutional theory.

\section{INTEGRATION OF THE FOUR THEORETICAL MODELS}

In this study we build upon the theoretical model proposed by Zhu et al. (2006), by integrating IDT,TOE, UET and institutional theory to propose an integrative conceptual framework (See fig. 1). The perceived characteristics are represented by (1) technology, organisation and environment in TOE model; (2) coercive pressure, normative pressure and mimetic pressure in Institutional theory; (3) age, education, group homogeneity, experience in UET. These factors are used as the independent variables that may negatively or positively influence technology dependent variables in the proposed theoretical model such as evaluation, adoption and routinisation in (fig 1 ).

Evaluation Stage: Evaluation stage is where a firm evaluates potential benefits provided by eSCM. This is the stage where a firm evaluate decision as to whether to use e-SCM before actual adoption. According Zhu et al. (2006) assimilation of innovation starts from organisation's initial awareness and evaluation of the innovation (Rogers, 1995) argue that the initial stage "amounts both to identifying and priorotising needs and problems on one hand and searching the organisation's environment to locate innovations of potential usefulness to meet organisational challenges". The degree to which e-SCM fits the problem to be solved will greatly influence the decision to implement e-SCM systems for an organisation. In this study the evaluation model propounded by Zhu will be used. The measurement aims at improving firm's performance in value activities such as market expansion, cost reduction and supply chain coordination.

Adoption Stage: Adoption is the stage where an organisation finally decides to a use e-SCM, in this case financial resources need to be channelled into acquisition of the technology and related IT services for effective running of the new systems. Zhu et al. (2006) emphasis that adoption of new technology does not imply wide usage among acquiring firms. The technology can be adopted by the firm but workers may not use it due resistance to change or sociopolitical factors.

Routinisation Stage: Zhu et al. (2006) define routinisation "as the stage in which e-business is widely used as an integral part in a firm's value chain activities". Routinisation may be regarded as the final stage in which e-SCM is widely used as integral part of the organisations supply chain activities. In this instance, the innovation (e-SCM) has gone through evaluation and adoption stage and is finally installed in the organisation and is widely used in the organisation on constant basis to improve the entire business process of SMEs. The following model provides insight into e-SCM diffusion in a developing economy. 


\section{Technology Context}

- Perceived cost/benefits

- Complexity

- Technology integration

- Daimar O namiatr.

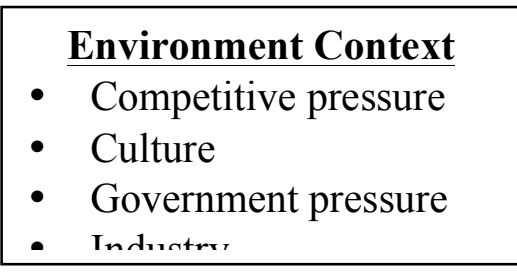

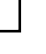
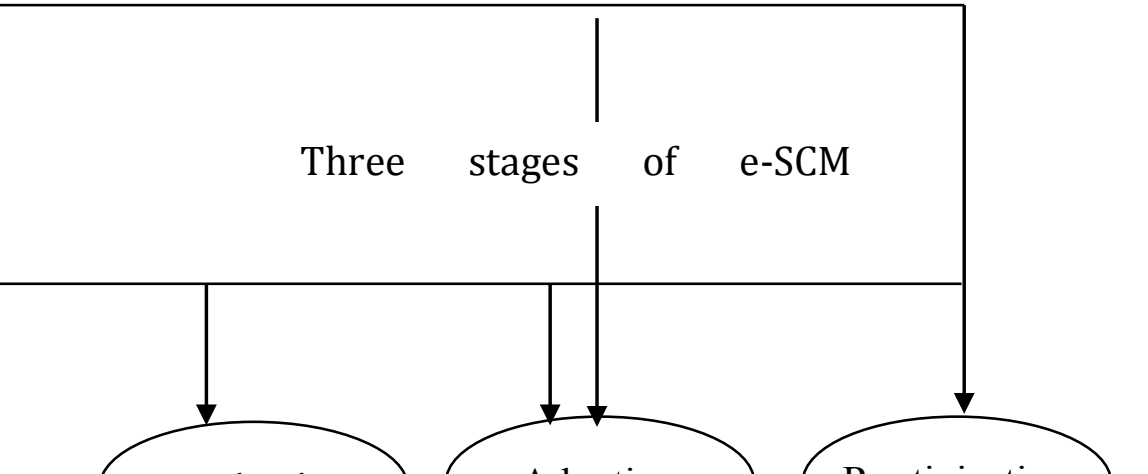

Organisational Context

- Top management support

- Firm size

- CEO innovation

\section{Isomorphic Mechanisms}

- Coercive pressure

- Normative pressure

- Mimetic pressure

\section{TMT Characteristics}

- Age composition

- Education composition

- Group Homogeneity

- Experience

Figure I: Conceptual model for e-SCM diffusion by SMEs

In summary after reviewing management and innovation diffusion models and considering the distinctive characteristics of e-SCM, we proposed an integrated conceptual model (Figure 1) in which the three-stage assimilation is influenced by technology context, environment context organisational context and isomorphic mechanisms. As stated earlier the conceptual model in this study extend the work Zhu et al. (2006), by including UET which explains how the characteristics of top management influence innovation adoption. In the next section we develop a number of propositions, which will guide future empirical study of the insights advanced in this research.

\section{Technological Context}

\section{PROPOSITIONS}

Technological context consists of perceived cost/expected benefits, complexity, technology integration, and security and privacy. Perceived benefits are explained as sets of expected advantages accruing to an organisation as a result of innovation. The benefits can be direct or indirect (Chwelos, Benbasat, \& Dexter, 2001). Direct benefits include cost reduction and improved operational efficiency. Opportunities created out of innovation utilisation such as customer services are some of the indirect benefits (Seyal \& Rahman, 2007). Perceived cost 
and benefits are carefully considered before an enterprise initiate innovation adoption process, in order to recoup return on investment.

Complexity refers to "the degree to which an innovation is perceived as difficult to understand and use" (Rogers, 2003). Some of the complexities might include: Resistance to change by employees, untrained employees, unfit technological strategy, procedures complexity may come about as a result of non-customised solutions and incompabitlity with existing information technology (IT) systems (Tsai et al, 2010).

Security and Privacy: Security refers to the policies, procedures and technical measures used to prevent and reduce the rate at which an organisation's information systems is subject to alteration, stealing, physical damage, unauthorised access Ken and Jane (2012). This leads to our first proposition:

P1. E-SCM diffusion can be influenced by technological factors, even though they might have greater effect on the evaluation and adoption stages.

Organisational factors

Organisational factors consist of four variables top management support, firm size, prior IT experience, and Chief Executive Officer Innovativeness. According to Rogers (2003), organisational size is one of the determinants of innovation adoption. Jeyaraj, Rottman, \& Lacity (2006) argue that size of an organisation has long been at the centre of IT adoption and is considered to be an important predictor of IT adoption. Top management support and attitudes towards change have been found to influence technological innovation adoption (Daylami, Ryan, Olfman, \& Shayo, 2005; Gupta, Dasgupta, \& Gupta, 2008; Premkumar \& Potter, 1995). Hence top management support is believed to influence ICT innovation adoption (Daylami et al., 2005; Wilson, Daniel, \& Davies, 2008).

Innovativeness is the ability to open to new ideas and methods by which clients process information, take decisions and offer solutions to problems (Kirton, 2004; Marcati, Guido, \& Peluso, 2008). The organisations receptiveness to better and new ways critically influence adoption of innovations in SMEs (Marcati et al., 2008). Commitment of CEO/Owner and their perception of ICT benefits appear to be crucial to the successful adoption of a new ICT in small enterprises. Roger explains further that user's adoption intention and behaviour can be influence by accumulated experiences using new innovations. Bandura (1997), intimates that there is relationship between users' prior knowledge and their understanding of a new situation or context. In the case of e-SCM adoption, familiarity with EDI, Intranet, extranet, computers, B2B portal can have a direct influence upon user perceptions regarding innovation diffusion in SCM. Previous research have found prior experience to influence technology adoption decisions (Chan \& Chang, 2001; Forman \& Lippert, 2005; Igbaria, Guimaraes, \& Davis, 1995). This leads us to our second proposition:

P2: Technology context is likely to influence e-SCM evaluation, adoption and routinization, but its effect will be greater on adoption than routinization.

\section{ENVIRONMENT FACTORS}

The main sources of environmental factors are competitive pressure, trading partners, customers and government (Iacovou, Benbasat, \& Dexter, 1995). Competitive pressure was found to positively and significantly influence adoption of e-commerce among SMEs in (Ghobakhloo, Arias-Aranda, \& Benitez-Amado, 2011). Similarly, Jeyaraj et al. (2006) also 
identified competitive pressure as one of the best factors that influence organisational adoption of information systems innovation. Das and Gupta (1999) found in their study that companies operating in an environmental contexts in which governmental policies are not open and supportive, have low IT adoption rate. Therefore, it is believed that governmental support can influence e-SCM diffusion in SMEs. A study by Minguzzi and Passaro (2001) indicated that culture is an internal factor, which includes the characteristics of human resources and the degree of receptiveness to new ideas and change in business practice. It is recognized that culture is an important variable in technology mediated learning. Saffu, DeBerry-Spence, Dadzie, Walker, and Hinson (2008) found in their study of e-Commerce adoption by SMEs in Ghana that adoption is influenced by cultural factors within an organisation. This leads us to our third proposition:

P3. Environmental context is likely to influence evaluation, adoption and routinization, but its effect will be greater on adoption than routinization

\section{ISOMORPHIC MECHANISMS}

Coercive pressure construct is derived from DiMaggio and Powell's (1983) mechanisms through which change occurs. DiMaggio and Powel's three categories have been adopted as theoretical foundation for number of SCM research that consider isomorphism (Ting et al, 2013), Coercive pressures are associated with informal or formal pressures. Informal pressures may emanate from "cultural expectations in the society within which organisations function (DiMaggio \& Powel, 1983). Formal pressures may also arise from the need to satisfy government regulations, such as tax and accounting regulations and pollution control. Empirical evidence suggest that coercive pressures on organisation may stem from a variety of source including resources-dominant organisations, regulatory bodies, and parent corporations, and are built into exchange relationships (Salancik \& Pfeffer, 1978). Regarding e-SCM adoption, Liu, Ke, Wei, Gu, and Chen (2010) stated that, in situations whereby a powerful channel member adopt e-SCM, the member may succumb its partners into adoption, failure to do that may negatively affect the established dependent relationships. In line with this argument, the dependent partner may accept the powerful partner's request to adopt eSCM.

Mimetic pressures arises from uncertainty. DiMaggio and Powel (1983), argues that firms are likely to imitate others when they face uncertainty due to rapid technological change or market change. According to Fligstein, (1985); Goodstein, (1994) if similar organisations do things in a certain way that give rise to that particular course of action being legitimised or taken for granted throughout the sector others will follow to avoid the embarrassment of being perceived as less innovative or responsive. With regards to e-SCM adoption, more enterprises are likely to adopt the innovation in order not to be seen as technologically less advanced.

Normative pressures may arise from professionalism. DiMaggio and Powel (1983) described professionalism as "the collective struggle of members of an occupation to define the conditions and methods of their work and to establish a cognitive base and legitimisation for their occupational autonomy. They contended that organisational decision makers should turn to norms, standards and solutions that are institutionalised in their businesses and professional circles. The communality of professional practice in a given discipline creates and strengthens the related norms, which in turn, generate normative pressures on firms and compel them to adopt the common practice (John et al, 2001). This leads us to our fourth proposition:

P4. An isomorphic mechanism is likely to influence evaluation, adoption and routinization, but its effect will be greater on adoption than routinization. 


\section{UPPER ECHELON THEORY (UET)}

According to UET, Young managers appears to be risk takers than older managers and they are open to new ways and ideas (Hambrick \& Mason, 1984), therefore, old managers may avoid the temptation of introducing innovative technology in supply chain management activities. And that older managers are most likely to reject risky projects such as investment in information technology but rather protect well established social ties, retirement plans, and lifestyle.

Several authors have consistently argued that either the CEO or other central actors are positively related to receptivity to innovation. Hambrick and Mason (1984); Dwivedi, Papazafeiropoulo, Chuang, Nakatani, and Zhou (2009) empirically found that there is positive relationship between education composition of Top Management Team (TMT) and the extent of information technology adoption in SMEs, and that the more TMT receive education, they are more likely to come into contact with IT tools and their application in business. This leads to our fifth proposition:

P5. Top management characteristics is likely to influence evaluation, adoption and routinization, but its effect will be greater on adoption than routinization

\section{CONCLUSION}

The purpose of this study has been to develop firm level framework by integrating TOE model, IDT, UET, and institutional theory and to further investigate the effects of the factors at different stages of e-SCM diffusion of e-SCM by SMEs in Sub-Saharan Africa. The study highlights the fact that SMEs willingness to adopt e-SCM to enhance their business operations may be influenced by various technological, environmental, organisational and institutional factors. It is also argued in this paper that the ability of SMEs to adopt innovation is dependent upon how effective management evaluates the operational environment before the adoption. After the adoption, management may implement wide usage (routinization) of the e-SCM within the firm. The firm's adoption process of e-SCM will enhance SMEs' competitiveness in the face of a turbulent market environment where SMEs in LDCs are expected to compete on the same footing with their counterparts in advanced economies. A successful adoption of innovation (e-SCM), will however, be a function of how well the integration of the various important factors identified in this study are blended.

\section{Some Implications}

Management of SMEs from Sub-Saharan Africa will be required to adopt innovation in order to propel them to make inroads in local as well as the foreign market. The ability of SMEs to adopt e-SCM may depend on proper integration of standalone IT systems (computers, mobile phones, PDAs, internet, application softwares), with that of other network members in their supply chain leading to real-time sharing of information and other resources that the SMEs may lack. To avoid the tendency where customers regard products from SMEs in Sub-Saharan Africa as less innovative and less superior (Awuah \& Amal, 2011). Hence, SMEs have to ensure evaluation, adoption and the usage of e-SCM among their network members through learning and collaboration in order to ensure smooth realignment and implementation of the new systems. Policy makers in Sub-Saharan Africa should encourage and provide support systems to assist the SMEs in their transition and adoption stage, since regulatory and economic factors has emerged as critical factor determining innovations assimilations (Zhu et al., 2006). 


\section{Suggestions for the Future Research}

This study is primarily at conceptual level, and provided an integrated framework for e-SCM adoption. It will be important to conduct empirical research to increase our understanding of the extent to which SMEs in Sub-Saharan Africa may take advantage of the emerging e-SCM platform in order to match MNCs in advanced economies in an attempt to produce and deliver competitive product and services.

\section{References}

Ajzen, I. (1991). The theory of planned behavior. Organisational Behavior and Human Decision Processes, 50(2), $179-211$.

Ajzen, I., \& Fishbein, M. (2005). The influence of attitudes on behavior. The handbook of attitudes, $173,221$.

Alam, S. S., \& Ahsan, N. (2007). "ICT adoption in Malaysian SMEs from service sector: preliminary findings", Journal of Internet Banking and Commerce, Vol. 12 No. 3, pp. 1-11.

Archer, N., Wang, S., \& Kang, C. (2008). Barriers to the adoption of online supply chain solutions in small and medium enterprises. Supply Chain Management: An International Journal, 13(1), 73-82.

Awa, H. O., Awara, N. F., \& Lebari, E. D. (2015). Critical factors inhibiting electronic commerce (EC) adoption in Nigeria: a study of operators of SMEs. Journal of Science and Technology Policy Management, 6(2).

Awuah, G. B., \& Amal, M. (2011). Impact of globalization: The ability of less developed countries'(LDCs') firms to cope with opportunities and challenges. European Business Review, 23(1), 120-132.

Bandura, A. (1997). Self-efficacy: The exercise of control: New York: Freeman.

Cagliano, A. C., De Marco, A., Rafele, C., Bragagnini, A., Gobbato, L., \& Al-Mashari, M. (2015). Analysing the diffusion of a mobile service supporting the e-grocery supply chain. Business Process Management Journal, 21(4).

Chan, Y.-K., \& Chang, C.-C. (2001). Image matching using run-length feature. Pattern Recognition Letters, 22(5), 447-455.

Chang, S.-I., \& Tsia, Y.-F. (2006). Critical Factors of E-SCM Adoption on Small and Medium Sized Enterprises Performance: An Empirical Study. IJEBM, 4(2), 159-172.

Chwelos, P., Benbasat, I., \& Dexter, A. S. (2001). Research report: Empirical test of an EDI adoption model. Information systems research, 12(3), 304-321.

Compeau, D., Higgins, C. A., \& Huff, S. (1999). Social cognitive theory and individual reactions to computing technology: A longitudinal study. MIS Quarterly, 145-158.

Compeau, D. R., \& Higgins, C. A. (1995). Computer self-efficacy: Development of a measure and initial test. MIS Quarterly, 189-211.

DasGupta, D. (1999). An overview of artificial immune systems and their applications: Springer.

Davis, F. D., Bagozzi, R. P., \& Warshaw, P. R. (1989). User acceptance of computer technology: a comparison of two theoretical models. Management science, 35(8), 982-1003.

Daylami, N., Ryan, T., Olfman, L., \& Shayo, C. (2005). “System sciences”, HICSS ‘05, Proceedings of the 38th Annual Hawaii International Conference, Island of Hawaii, 3-6 January.

DiMaggio, P., \& Powell, W. W. (1983). The iron cage revisited: Collective rationality and institutional isomorphism in organisational fields. American Sociological Review, 48(2), 147-160.

Dwivedi, Y. K., Papazafeiropoulo, A., Chuang, T.-T., Nakatani, K., \& Zhou, D. (2009). An exploratory study of the extent of information technology adoption in SMEs: an application of upper echelon theory. Journal of enterprise information management, 22(1/2), 183-196.

Dwivedi, Y. K., Papazafeiropoulo, A., Ramdani, B., Kawalek, P., \& Lorenzo, O. (2009). Predicting SMEs' adoption of enterprise systems. Journal of enterprise information management, 22(1/2), 10-24.

Fligstein, N. (1985). The spread of the multidivisional form among large firms, 1919-1979. Advances in Strategic Management, 17, 55-78. 
Musa, A. \& Iddris, F. (2016). An Integrated Framework for Diffusion of e-SCM by SMES in Sub-Saharan Africa. Archives of Business Research, 4(2), 48-57.

Forman, H., \& Lippert, S. K. (2005). Toward the development of an integrated model of technology internalization within the supply chain context. The International Journal of Logistics Management, 16(1), 4-27.

Ghobakhloo, M., Arias-Aranda, D., \& Benitez-Amado, J. (2011). Adoption of e-commerce applications in SMEs. Industrial Management \& Data Systems, 111(8), 1238-1269.

Giménez, C., \& Lourenço, H. R. (2008). E-SCM: internet's impact on supply chain processes. International Journal of Logistics Management, the, 19(3), 309-343.

Goodstein, J. D. (1994). Institutional pressures and strategic responsiveness: Employer involvement in workfamily issues. Academy of Management Journal, 37(2), 350-382.

Guercini, S., \& Runfola, A. (2015). Internationalization through E-Commerce. The Case of MultiBrand Luxury Retailers in the Fashion Industry. International Marketing in the Fast Changing World (Advances in International Marketing, Volume 26) Emerald Group Publishing Limited, 26, 15-31.

Gupta, B., Dasgupta, S., \& Gupta, A. (2008). Adoption of ICT in a government organisation in a developing country: An empirical study. The Journal of Strategic Information Systems, 17(2), 140-154.

Hambrick, D. C., \& Mason, P. A. (1984). Upper echelons: The organisation as a reflection of its top managers. Academy of management review, 9(2), 193-206.

Hill, T., Smith, N. D., \& Mann, M. F. (1987). Role of efficacy expectations in predicting the decision to use advanced technologies: The case of computers. Journal of applied psychology, 72(2), 307.

Iacovou, C. L., Benbasat, I., \& Dexter, A. S. (1995). Electronic data interchange and small organisations: adoption and impact of technology. MIS Quarterly, 465-485.

Iddris, F. (2012). Adoption of E-Commerce solutions in small and medium-sized enterprises in Ghana. European Journal of Business and Management, 4(10), 48-57.

Igbaria, M., Guimaraes, T., \& Davis, G. B. (1995). Testing the determinants of microcomputer usage via a structural equation model. Journal of Management Information Systems, 87-114.

Jeyaraj, A., Rottman, J. W., \& Lacity, M. C. (2006). A review of the predictors, linkages, and biases in IT innovation adoption research. Journal of Information Technology, 21(1), 1-23.

Ke, W., Liu, H., Wei, K. K., GU, J., \& Chen, H. (2006). The Effects of Relational and Institutional Factors on Electronic Supply Chain Management Adoption: Does Organisational Culture Matter? PACIS 2006 Proceedings, 83.

Ken, L., \& Jane, L. (2012). Management Information Systems: Managing the Digital Firm Ed 12 Prentice Hall

Kirton, M. J. (2004). Adaption-innovation: In the context of diversity and change: Routledge.

Lancaster, S., Yen, D. C., \& Ku, C.-Y. (2006). E-supply chain management: an evaluation of current web initiatives. Information Management \& Computer Security, 14(2), 167-184.

Liu, H., Ke, W., Wei, K. K., GU, J., \& Chen, H. (2010). The role of institutional pressures and organisational culture in the firm's intention to adopt internet-enabled supply chain management systems. Journal of Operations Management, 28(5), 372-384.

Marcati, A., Guido, G., \& Peluso, A. M. (2008). The role of SME entrepreneurs' innovativeness and personality in the adoption of innovations. Research Policy, 37(9), 1579-1590.

Martin, L. M., \& Matlay, H. (2001). "Blanket" approaches to promoting ICT in small firms: some lessons from the DTI ladder adoption model in the UK. Internet research, 11(5), 399-410.

Mathieson, K. (1991). Predicting user intentions: comparing the technology acceptance model with the theory of planned behavior. Information systems research, 2(3), 173-191.

Minguzzi, A., \& Passaro, R. (2001). The network of relationships between the economic environment and the entrepreneurial culture in small firms. Journal of Business Venturing, 16(2), 181-207.

Molla, A., \& Licker, P. S. (2005a). ECommerce adoption in developing countries: a model and instrument. Information \& management, 42(6), 877-899. 
Molla, A., \& Licker, P. S. (2005b). Perceived e-readiness factors in e-commerce adoption: An empirical investigation in a developing country. International Journal of Electronic Commerce, 10(1), 83-110.

Moore, G. C., \& Benbasat, I. (1991). Development of an instrument to measure the perceptions of adopting an information technology innovation. Information systems research, 2(3), 192-222.

Premkumar, G., \& Potter, M. (1995). Adoption of computer aided software engineering (CASE) technology: an innovation adoption perspective. ACM SIGMIS Database, 26(2-3), 105-124.

Rogers, E. M. (1995). Diffusion of innovations. (4th Ed.). New York: Free Press Publishers.

Rogers, E. M. (2003). The communication of innovation: The Need for Internet access multiplies along with obstacles (Vol. Rogers, E. M).

Rogers, M. (1998). The definition and measurement of innovation: Melbourne Institute of Applied Economic and Social Research Parkville, VIC.

Saffu, K., DeBerry-Spence, B., Dadzie, K. Q., Walker, J. H., \& Hinson, R. (2008). Strategic value and electronic commerce adoption among small and medium-sized enterprises in a transitional economy. Journal of Business \& Industrial Marketing, 23(6), 395-404.

Salancik, G. R., \& Pfeffer, J. (1978). A social information processing approach to job attitudes and task design. Administrative science quarterly, 224-253.

Sambasivan, M., Abidin Mohamed, Z., \& Nandan, T. (2009). Performance measures and metrics for e-supply chains. Journal of enterprise information management, 22(3), 346-360.

Seyal, A. H., \& Rahman, N. (2007). The influence of external variables on the executives' use of the internet. Business Process Management Journal, 13(2), 263-278.

Skjøtt-Larsen, T., Kotzab, H., \& Grieger, M. (2003). Electronic marketplaces and supply chain relationships. Industrial Marketing Management, 32(3), 199-210.

Taylor, S., \& Todd, P. A. (1995). Understanding information technology usage: A test of competing models. Information systems research, 6(2), 144-176.

Thong, J. Y. (1999). An integrated model of information systems adoption in small businesses. Journal of Management Information Systems, 15(4), 187-214.

Uzoka, F.-M. E. (2008). Organisational influences on e-commerce adoption in a developing country context using UTAUT. International Journal of Business Information Systems, 3(3), 300-316.

Venkatesh, V., \& Davis, F. D. (1996). A model of the antecedents of perceived ease of use: Development and test*. Decision sciences, 27(3), 451-481.

Venkatesh, V., \& Davis, F. D. (2000). A theoretical extension of the technology acceptance model: Four longitudinal field studies. Management science, 46(2), 186-204.

Venkatesh, V., Morris, M. G., Davis, G. B., \& Davis, F. D. (2003). User acceptance of information technology: Toward a unified view. MIS Quarterly, 425-478.

White, G. R., Afolayan, A., \& Plant, E. (2014). Challenges to the Adoption of E-commerce Technology for Supply Chain Management in a Developing Economy: A Focus on Nigerian SMEs E-commerce Platform Acceptance (pp. 23-39): Springer.

Wilson, H., Daniel, E., \& Davies, I. A. (2008). The diffusion of e-commerce in UK SMEs. Journal of Marketing Management, 24(5-6), 489-516.

Zhu, K., Kraemer, K. L., \& Xu, S. (2006). The process of innovation assimilation by firms in different countries: a technology diffusion perspective on e-business. Management science, 52(10), 1557-1576. 